\title{
VARIABILIDADE ESPACIAL DE PARÂMETROS E INDICADORES DE QUALIDADE DA ÁGUA NA SUB-BACIA HIDROGRÁFICA DO IGARAPÉ SÃO FRANCISCO, RIO BRANCO, ACRE, BRASIL
}

\author{
VARIABILIDAD ESPACIAL DE PARÁMETROS E INDICADORES DE CALIDAD \\ DEL AGUA EN SUBCUENCA HIDROGRÁFICA DEL IGARAPÉ SÃO FRANCISCO, \\ RIO BRANCO, ACRE, BRASIL
}

\author{
SPATIAL VARIABILITY OF WATER QUALITY PARAMETERS AND \\ INDICATORS IN THE SÃO FRANCISCO STREAM SUB-BASIN, IN RIO BRANCO, \\ ACRE, BRAZIL
}

Giuliana Marconati Santi ${ }^{1}$, Cydia de Menezes Furtado ${ }^{2}$, Rui Sant’Ana de Menezes ${ }^{2}$, Erlei Cassiano Keppeler ${ }^{3}$

\section{Resumo}

É importante identificar a qualidade da água, bem como a sua vulnerabilidade à atividade humana, tendo em vista a gestão dos recursos hídricos discutida globalmente e, em menor instância pela sazonalidade. O objetivo deste trabalho é avaliar os parâmetros de qualidade de água ao longo do igarapé São Francisco, correlacionando com as possíveis fontes poluidoras oriundas especialmente, das características antrópicas, e observar a variação sazonal desses parâmetros. A metodologia utilizada contemplou amostras de água coletadas na sub-superficie: $\mathrm{pH}$, oxigênio dissolvido, condutividade elétrica, turbidez, sólidos totais, nitrogênio total, fósforo total, demanda bioquímica de oxigênio, demanda química de oxigênio e coliformes fecais. Análise de componentes principais foi utilizada para agrupar as estações de coleta, que não revelou tendência de agregação das estações de coletas em eixos nos dois períodos avaliados. As estações das pontes, onde possivelmente animais mortos são jogados, foram as mais impactadas no trecho avaliado.

Palavras-chave: Gestão, recursos hídricos, Amazônia.

\section{Resumen}

Es importante identificar la calidad del agua, así como su vulnerabilidad a la actividad humana, con miras a la gestión de los recursos hídricos discutida globalmente y, en menor escala, por su estacionalidad. El objetivo de este estudio es evaluar los parámetros de calidad del agua a lo largo del igarapé San Francisco, en correlación con las posibles fuentes de contaminación procedentes, sobre todo, de las características antropogénicas, y observar la variación estacional de estos parámetros. La metodología utilizada ha considerado muestras de agua recogidas en la subsuperficie y se han evaluado los parámetros: $\mathrm{pH}$, oxígeno disuelto, conductividad eléctrica, turbidez, sólidos totales, nitrógeno total, fósforo total, demanda bioquímica de oxígeno, demanda química de oxígeno y coliformes fecales. Se ha utilizado el análisis de componentes principales para agrupar las estaciones de muestreo, que no ha presentado tendencia a la agregación de las estaciones de recolección en ejes en los dos períodos evaluados. Las estaciones de los puentes, donde, posiblemente, los animales muertos son arrojados, fueron las más afectadas en el tramo evaluado.

Palabras clave: gestión, recursos hídricos, Amazonia.

\begin{abstract}
It is important to assess water quality, as well as its vulnerability to human activity, towards water resources management, globally discussed, and to a lesser extent, seasonally. The aim of this work is to evaluate the water quality parameters along the São Francisco River, correlating them to possible sources of pollution, especially derived from anthropization, and to observe seasonal variations in these parameters. Methods involved collecting subsurface water samples and assessing $\mathrm{pH}$, dissolved oxygen, electrical conductivity, turbidity, total dissolved solids, total nitrogen, total phosphorus, biochemical oxygen demand, chemical oxygen demand and fecal coliform bacteria. Main components analysis was used for grouping sampling sites. No aggregation tendencies were found for the axes of sampling sites axes in both studied periods.
\end{abstract}


Sites next to bridges, where dead animals are possibly thrown, were those of highest impact in the studied section.

Key words: Management, water resources, Amazon.

\section{Introdução.}

Diversos estudos têm mostrado a preocupação com a poluição das bacias hidrográficas (Wiesel, 2002; Botalova \& Schuarzbauer, 2011). Como também cita Campanha et al. (2010), e em menor instância, a variação pela sazonalidade.

É importante identificar a qualidade da água. bem como verificar a sua vulnerabilidade à atividade humana, tendo em vista a importância da gestão dos recursos hídricos no que se refere ao seu gerenciamento, uso e conservação.

A sub-bacia hidrográfica do igarapé São Francisco é contribuinte da margem esquerda do rio Acre. Ocupa uma área de aproximadamente 45.000 ha, com densidade de drenagem de $0,76 \mathrm{~km}^{2}$. De acordo com a classificação do padrão de drenagem de redes fluviais propostas por Ab’saber (1985), a sub-bacia hidrográfica do igarapé São Francisco apresenta um sistema de drenagem dendrítica, tendo como principal canal de drenagem o Igarapé São Francisco que, ao longo de seu curso, recebe descarga de vários igarapés de menor proporção, compondo uma rede fluvial de cursos d'água perenes e intermitentes, com três igarapés principais: Saituba, Dias Martins e Batista, afluentes da sua margem direita. Vários afluentes do Igarapé São Francisco apresentam parte do esgoto captado por redes coletoras lançados sem tratamento, tornando-se receptor de uma grande quantidade de resíduos sólidos. Cabe ainda ressaltar que toda a poluição lançada é carreada para o Rio Acre.

Os cursos d’água da bacia hidrográfica do igarapé São Francisco são enquadrados na categoria "rios de águas brancas", caracterizados por possuírem uma coloração amarelada (água barrenta) resultante do transporte elevado de material em suspensão (Sioli, 1985). Toda a rede de drenagem que compõe a bacia hidrográfica possui importante papel social e na regulação do ciclo hidrológico.

Diante do exposto, este trabalho tem o objetivo de avaliar os parâmetros de qualidade de água, ao longo de um trecho do igarapé São Francisco, correlacionando com as possíveis fontes poluidoras oriundas especialmente, das características antrópicas. Adicionalmente, observar a variação sazonal desses parâmetros.

\section{Material e Métodos.}

Caracterização da área de estudo Clima.

O clima do estado do Acre é equatorial quente e úmido: a estação seca, popularmente, é denominada de verão amazônico sendo para a Amazônia, época de baixo regime fluvial, período este que se estende de junho a setembro. A estação chuvosa se caracteriza por chuvas constantes, iniciando-se no mês de novembro, prolongando-se até o final de abril. Essa época do ano, popularmente, é denominada inverno amazônico, configurando-se, então, como época de alto regime fluvial na região.

A temperatura média anual situa-se na faixa de $24^{\circ} \mathrm{C}$. De acordo com a classificação de Köppen (1948) o clima da região está classificado como pertencente ao grupo AM com chuvas do tipo monçônico, temperatura média do mês mais frio superior a $18^{\circ} \mathrm{C}$ e uma estação seca de pequena duração, não chegando a influenciar significativamente a cobertura vegetal.

A temperatura média mensal apresenta oscilação reduzida, variando de $24^{\circ} \mathrm{C}$ a $26^{\circ} \mathrm{C}$, observando-se um leve declínio nos meses de junho a agosto. Neste trimestre, o fenômeno conhecido regionalmente como “friagem”, ocasionado pela penetração de frentes polares, provoca redução na temperatura em valores de até $5^{\circ} \mathrm{C}$, por um período de poucos dias.

A precipitação média anual supera, com freqüência, os $2.000 \mathrm{~mm}$, distribuída principalmente nos meses de outubro a maio. Os maiores índices pluviométricos são observados de dezembro a março, chegando a $800 \mathrm{~mm}$ no período, e os meses mais secos são junho, julho e agosto, com médias de 150 $\mathrm{mm}$, ocorrendo estiagens de até 30 dias.

Dados de evaporação mostram totais anuais de 650 mm (Nabil, 1982), bem inferiores aos de evapotranspiração $(1.300 \mathrm{~mm})$ obtidos por balanços hídricos estimados pelos métodos de Thornthwaite, Turc ou Penman (Bursztyn et al., 1993).

Geologia e geomorfologia

A geologia da bacia do igarapé São Francisco pode ser caracterizada em três tipos bem distintos. O primeiro tipo, o mais comum em toda a área, são seções pequenas e incompletas que somente afloram na calha dos rios e estão, via de regra, recobertas por sedimentos inconsolidados, holocênicos, pertencentes à planície de inundação. Essas seções ficam, durante o inverno amazônico (período chuvoso), totalmente submerso. O segundo tipo é encontrado subordinadamente com relação ao primeiro, também nas calhas dos rios, cobertos, por sedimentos recentes da planície de inundação. São afloramentos de maior ocorrência com relação ao primeiro, mostrando registros de partes de ciclos fluviais posteriores. O terceiro tipo de afloramento encontrado na área que se localiza fora da planície de inundação, em cortes de estradas (Acre, 2005).

As seções que afloram nas calhas dos igarapés da bacia, dentro da planície de inundação, possuem, em 
geral, de três a cinco metros de exposição, geralmente recobertas por sedimentos inconsolidados, entulhados com restos vegetais, tais como raízes transportadas pela última cheia, sedimentos que são de idade recente. As rochas sedimentares que aparecem nos afloramentos ao longo dos igarapés são constituídas por argilitos, arenitos finos a médios e siltitos argilosos (Acre, 2000).

Deve-se dar ênfase aos argilitos pelo fato de que aparecem como constituintes básicos dessa seqüência terciária, sendo que essa unidade litológica engloba praticamente a maioria das feições geológicas encontradas subordinando os outros constituintes litológicos associados. O Igarapé São Francisco também apresenta essas feições, onde encontramos locais em estágios diferenciados de formação. Isso indica que o ambiente que atualmente esta predominando é de alta energia com escavações e deposições provocadas pela dinâmica da drenagem e da sua sazonalidade marcada pelos períodos de seca e enchentes (Acre, 2005).

Área de estudo

A descrição da localização das cinco estações de coleta ao longo do Igarapé São Francisco

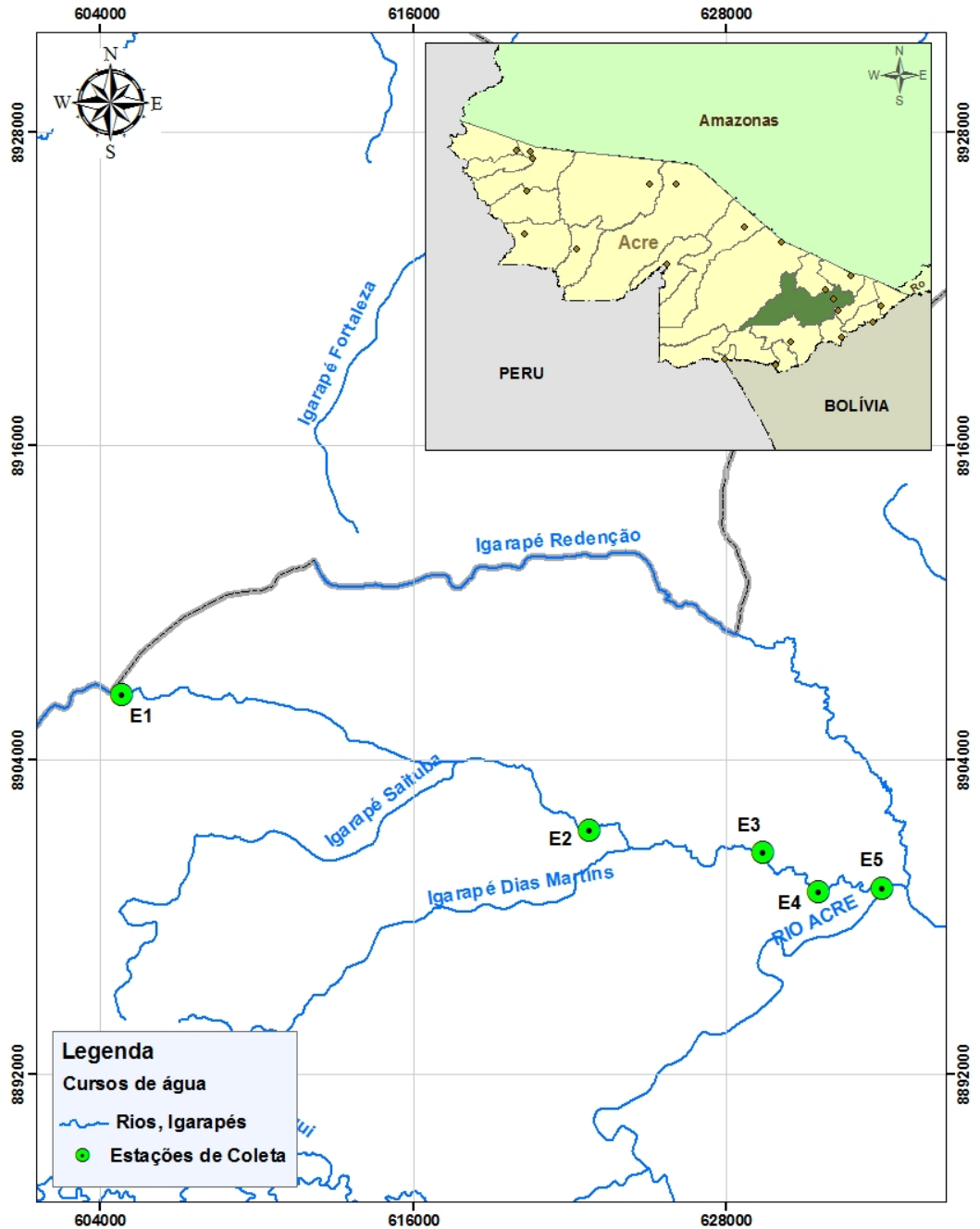

Figura 1. Localização e distribuição das cinco estações de coleta ao longo de um trecho do igarapé São Francisco (Fonte: Vectra Engenharia). (Fig. 1), a saber: Estação de coleta 1 (S: 0953'27"; W: 06802'37"): Ramal Santa Luzia Km 14. Estação de coleta 2 (S: 0956’41”; W: 06749'10") Ponte São Francisco bairro Distrito Industrial. Estação de coleta 3 (S: 0957'30"; W: 06748'00"). Ponte São Francisco Avenida Getúlio Vargas. Estação de coleta 4 (S: 0957'25”; W: 06746'40”): Ponte São Francisco bairro São Francisco. Estação de coleta 5 (S: 0957'25”; W: 06752'48”): Foz do igarapé São Francisco.

O trabalho foi realizado ao longo de um trecho do igarapé São Francisco com extensão de vinte e cinco quilômetros, em cinco estações de coletas situadas: uma na principal nascente; três na área urbana; e uma na foz (Figura 1).

Amostragem

As amostras de água foram coletadas na subsuperficie com profundidade aproximada de $15 \mathrm{~cm}$ e transportadas de acordo com o Guia de Coleta e Preservação de Amostras da Cetesb (1998), para o laboratório da Unidade de Tecnologia de alimentos da

Universidade Federal do Acre, nos períodos de seca (águas baixas) e período chuvoso (águas altas), correspondendo aos meses de maio e setembro de 2009.

Em cada estação de coleta foi estabelecida um ponto de amostragem: margem esquerda. A localização de cada estação de coleta foi obtida com GPS marca Garmin 12XL, utilizado datum SAD 69.

Foram estudadas 11 parâmetros físicos e químicos: pH (potenciômetro), oxigênio dissolvido pelo método winkler (Golterman, 1979), condutividade elétrica (condutivímetro), turbidez (turbidímetro), sólidos totais dissolvidos (método gravimétrico, $105{ }^{\circ} \mathrm{C}$, de acordo com a ABNT NBR No 10664/1989), nitrogênio total e fósforo total (método de digestão e do ácido ascórbico com posterior leitura em espectrofotômetro (APHA, 1995), demanda bioquímica de oxigênio $\left(\mathrm{DBO}_{5}\right)$ pelo método de Winkler, com período de incubação de 5 dias, a $2{ }^{\circ} \mathrm{C}$ (ABNT NBR 12614, 1992), fosfato (APHA, 1992) e 
demanda química de oxigênio (DQO) pelo método descrito em APHA, (1992), óleos e graxas.

Para a análise de coliformes (fecais) termotolerantes, a metodologia empregada foi a de tubos múltiplos, recomendada pelo Conselho Nacional do Meio Ambiente - Conama (2005), que se fundamenta no Standard Methods (APHA, 1995).

Uma análise de Componentes Principais (ACP) foi realizada para ordenar os períodos sazonais, as unidades amostrais e as parâmetros físicos e químicos, com o propósito de explicar a dinâmica dessas variáveis no sistema. Para esta análise, foi utilizado a análise de agrupamento foi processada segundo a metodologia proposta por Sneath \& Sokal (1973). Foi, assim, aplicada aos dados, utilizando-se como coeficiente de semelhança entre as estações a distância euclidiana, que é um coeficiente de dissimilaridade, pois quanto menor a distância entre dois locais mais similares eles são, conforme as características consideradas. A estratégia de agrupamento adotada foi a Average Linkage - UPGMA (Unweighted Pair Group Method with Arithmetic Averages). O programa utilizado foi o Statistica (Statsoft, 2004).

\section{Resultados e discussão.}

Parâmetros físicos e químicos e coliformes fecais

Os parâmetros físicos e químicos estão apresentados na figura 2. As estações de coleta 1, 2, 3, 4 , e 5 no período da seca e apresentaram valores de oxigênio que variaram de 0,8 a 5,0 (Fig. 2A). A oscilação do oxigênio foi expressiva, cerca de cinco vezes sobre o menor valor. Estes foram inferiores ao limite estabelecido (>=5mg.L ${ }^{-1}$ ) pela Resolução Conama (Brasil) n 357/2005 para as águas de classe 2, de água doce. As águas desta classe são destinadas: a) ao abastecimento para consumo humano, após tratamento convencional; b) a proteção das comunidades aquáticas; c) a recreação de contato primário, tais como natação, esqui aquático e mergulho, estabelecidos pela Resolução (Brasil) $n^{0}$. 274 de 2000; d) a irrigação de hortaliças, plantas frutíferas e de parques, jardins, campos de esporte e lazer, com os quais o público possa vir a ter contato direto; e e) a aqüicultura e a atividade de pesca. A oscilação do oxigênio para menos ocorreu, devido ao aumento dos compostos orgânicos e nutrientes, havendo uma demanda maior por oxigênio dissolvido na água pelos microrganismos aeróbios. Estes valores, próximos da anoxia, foram similares àqueles observados em alguns períodos nos rios da bacia amazônica e da sub-bacia do Purus, a qual pertence o igarapé avaliado (Silva et al., 2009), bem como os demais valores para o tipo de despejo que recebem.

Os valores de $\mathrm{pH}$ oscilaram de neutro a levemente ácido (Fig. 2B), revelando baixa variabilidade espacial e sazonal, e esteve dentro dos padrões recomendados, entre 6 e 9, pela resolução Conama (Brasil) n. ${ }^{\circ}$ 357/2005. O pH medido das amostras, nas cinco estações de coleta, no período de cheia deveriam ter se apresentado mais baixos devido às águas da precipitação atmosférica serem mais ácidas, porém, este período em 2009 fora atípico, registrando-se uma redução no índice pluviométrico comparado ao ano de 2008. Não houve variação de pH em relação às diferenças de impacto.

As oscilações de $\mathrm{DBO}_{5}$ entre as estações chegaram a variar quase dez vezes, no período de seca. A DBO encontrada na estação 1 de $30 \mathrm{mg} . \mathrm{L}^{-1}$ (principal nascente do igarapé São Francisco) foi mais elevada que na estação 5 de 3,20 mg. $L^{-1}$ (foz do igarapé São Francisco), mostrando a capacidade de autodepuração do igarapé São Francisco. As estações 1, 2 e 3 no período da seca (Fig. 2D) excederam o limite da Resolução Conama (Brasil) n ${ }^{\circ} 357 / 2005$ que estabelece o valor de até $5 \mathrm{mg} \cdot \mathrm{L}^{-1}$. No período chuvoso todas as estações de coleta mantiveram-se dentro do limite estabelecido pela Resolução.Observase na figura $2 \mathrm{D}$, que os maiores valores em todas as estações de coleta foram encontrados no período seco, revelando maior concentração de matéria orgânica, revelando maior poluição nesse período.

Quanto à condutividade elétrica, demonstrou valores elevados no período de seca (Fig. 2C), considerando que a condutividade elétrica reflete a concentração de íons em solução (Wetzel \& Likens, 2001), provavelmente houve concentração de sais solúveis na água, devido ao nível fluviométrico ser mais baixo nessa época. Valores similares aos observados neste estudo foram relatados no Rio dos Sinos, Rio Grande do Sul, sendo um rio caracterizado como de água de baixa qualidade, com fortes atividades antrópicas naquele local (Blume et al., 2010).

A demanda química de oxigênio, variável importante no controle dos efluentes industriais que, avalia a quantidade de oxigênio dissolvido consumido em meio ácido que leva à degradação de matéria orgânica biodegradável ou não. Acompanhou valores altos (Fig. 2E) juntamente com a demanda bioquímica de oxigênio para baixos valores de oxigênio dissolvido, demonstrando que o material presente nestas estações era biodegradável e não biodegradável.

Observa-se que a variável nitrogênio total apresentou maior concentração no período seco, provavelmente devido aos processos de decomposição da matéria orgânica, liberando compostos nitrogenados (Wetzel, 1993). O lançamento de efluentes domésticos, sem tratamento, aumentaram consideravelmente a concentração desta variável no ambiente aquático. As estações de coleta 3 e 5 apresentaram maiores concentrações nos dois períodos de coleta, mostrando que não houve influência sazonal (Fig. 2F).

O fósforo total (PT) é considerado um dos melhores indicadores do conteúdo de nutrientes em qualquer ecossistema (Payne, 1986), e sabe-se que, 
nos períodos chuvosos há uma maior concentração de nutrientes nos ambientes aquáticos, pelas chuvas ser uma fonte difusa (Silva et al., 2009). Altas concentrações de fósforo na água estão associadas com a eutrofização da mesma, provocando o desenvolvimento de algas ou outras plantas aquáticas indesejáveis em reservatório ou águas paradas (Bassoi \& Guazelli, 2004). Neste estudo, o fósforo total fez-se presente em concentrações consideradas baixas (Fig. 2G) nos dois períodos de coleta (períodos chuvoso e seco de 2009), todavia teve uma variação de cerca de cinqüenta vezes, quando comparou-se as estações 1 $\left(0,03 \mathrm{mg} . \mathrm{L}^{-1}\right)$ e $5(0,52)$, no período chuvoso, e no seco nas estações $2(0,61)$ e estação $5(0,06)$, embora inversamente.

Os sólidos totais dissolvidos apresentaram maiores valores no período chuvoso (Fig. 2H), o que era esperado devido ao pulso de inundação do igarapé. A turbidez seguiu o mesmo comportamento que esta variável, apresentando também maiores valores no período chuvoso (Fig 2I). Em geral, os teores de turbidez estão relacionados ao material em suspensão presente nos corpos d'água, e esta concentração aumenta no período de chuvas. Em períodos chuvosos, na microbacia hidrográfica do igarapé São Francisco a quantidade de material suspenso aumentou acentuadamente a turbidez, havendo indícios de carreamento de fósforo.

Quanto aos óleos e graxas, variaram no período inteiro de 0,01 a 0,14 (Fig. 2J), e seguiram o limite estabelecido pela legislação Conama (Brasil) $n^{0}$. 375/2005.

Esta resolução, para os coliformes fecais nas águas de classe 2 determina que o Número Mais Provável (NMP) é de 1000/100 mL. A Fig. 2K mostra a estação de coleta 2 (igarapé São Francisco no Distrito Industrial) nos dois períodos chuvoso de cheia e seca de 2009 excedeu esse limite permitido pelo CONAMA, portanto indicando que esse local é o mais influenciado por ações antropogênicas. Nas estações 1, 2 e 3, no período seco, os baixos valores de oxigênio $(1,01,0,80$ e 1,0) foram correlacionados com altas concentrações de coliformes fecais (400, 1600 e 900). Logo, a redução do $\mathrm{O}_{2}$ decorreu da grande concentração de bactérias e matéria orgânica, oriundas dos esgotos domésticos (Pinto et al., 2009).

A análise de componentes principais e coeficientes de correlação são apresentados nas figuras 3A, B, C, D. As estações de coletas apresentaram um agrupamento determinado pelas parâmetros físicos e químicos, onde as mais similares foram a período 1 e a 5 chuvoso, enquanto a 3 ficou mais isolada. Provavelmente isso se deu devido ao processo de autodepuração das águas do igarapé.

No período seco a maior similaridade foi entre as estações 2 e 3 , e a estação 1 por ser a principal nascente do igarapé apresentou menores valores nas variáveis analisadas, ocasionando o isolamento;

Nas figuras 3A e 3B, a análise de componentes principais confirma uma ótima explicalidade obtida, pois alcançou $82,02 \%$ na cheia, e $79,34 \%$ na seca. A maioria das variáveis localizadas no eixo negativo, como se pode observar na Fig. 3C, deu-se devido ao peso atribuído por todas as variáveis, exceto pelo peso atribuído aos coliformes fecais.

Em geral, foi observado padrão pouco diferenciado das variáveis avaliadas, considerando a sazonalizade, tendo em vista que as variáveis no período seco se organizaram principalmente no lado negativo do eixo. $\mathrm{Na}$ época seca, o peso maior foi para turbidez $(-0,95)$, fósforo total $(-0,94)$, coliformes fecais $(-0,94)$ e demanda química de oxigênio $(-0,86)$.

A época chuvosa também revelou um padrão diferente, onde as variáveis se distribuíram quase uniformemente nos eixos positivo e negativo, determinando os valores de sólidos totais dissolvidos, turbidez e de -0,99 para condutividade elétrica, turbidez, fósforo total, nitrogênio total, sólidos totais dissolvidos, e temperatura, enquanto as variáveis, OD, $\mathrm{DBO}_{5}, \mathrm{DQO}$, apresentando pesos respectivos. Logo, isso deu-se em razão dos pesos similares da maioria das variáveis, e só os coliformes fecais apresentaramse no lado positivo. Da mesma forma, o comportamento desta variável repetiu-se na época seca.

A análise multivariada não revelou tendência de agregação das parâmetros físicos e químicos em eixos nos dois períodos avaliados, e as variáveis do fator 1 apresentaram-se no eixo negativo, exceto os coliformes fecais, ao contrário do estudo realizado por Souza (2010), no Igarapé Preto em Cruzeiro do Sul, Acre, que observaram as variáveis temperatura, $\mathrm{pH}$, oxigênio dissolvido, demanda bioquímica de oxigênio, nitrogênio total, fósforo total, sólidos totais dissolvidos, turbidez e coliformes fecais na época chuvosa localizadas no eixo positivo, e estas mesmas varáveis da época seca no eixo negativo. Possivelmente, o Igarapé São Francisco apresenta grau de antropização maior que o Igarapé Preto, o que minimizou as mudanças nas parâmetros físicos e químicos proporcionadas pelas alterações do ciclo hidrológico.

Em geral, os resultados dos parâmetros físicos, químicos e microbiológicos indicaram característica natural da água, como por exemplo as chuvas, e considerada do ponto de vista geológico da região, e poluição oriunda principalmente de esgotos domésticos e industriais. Isso foi corroborado também nos estudos realizados por Souza \& Tundisi (2003), Menezes et al. (2009) e Silva et al. (2009). 

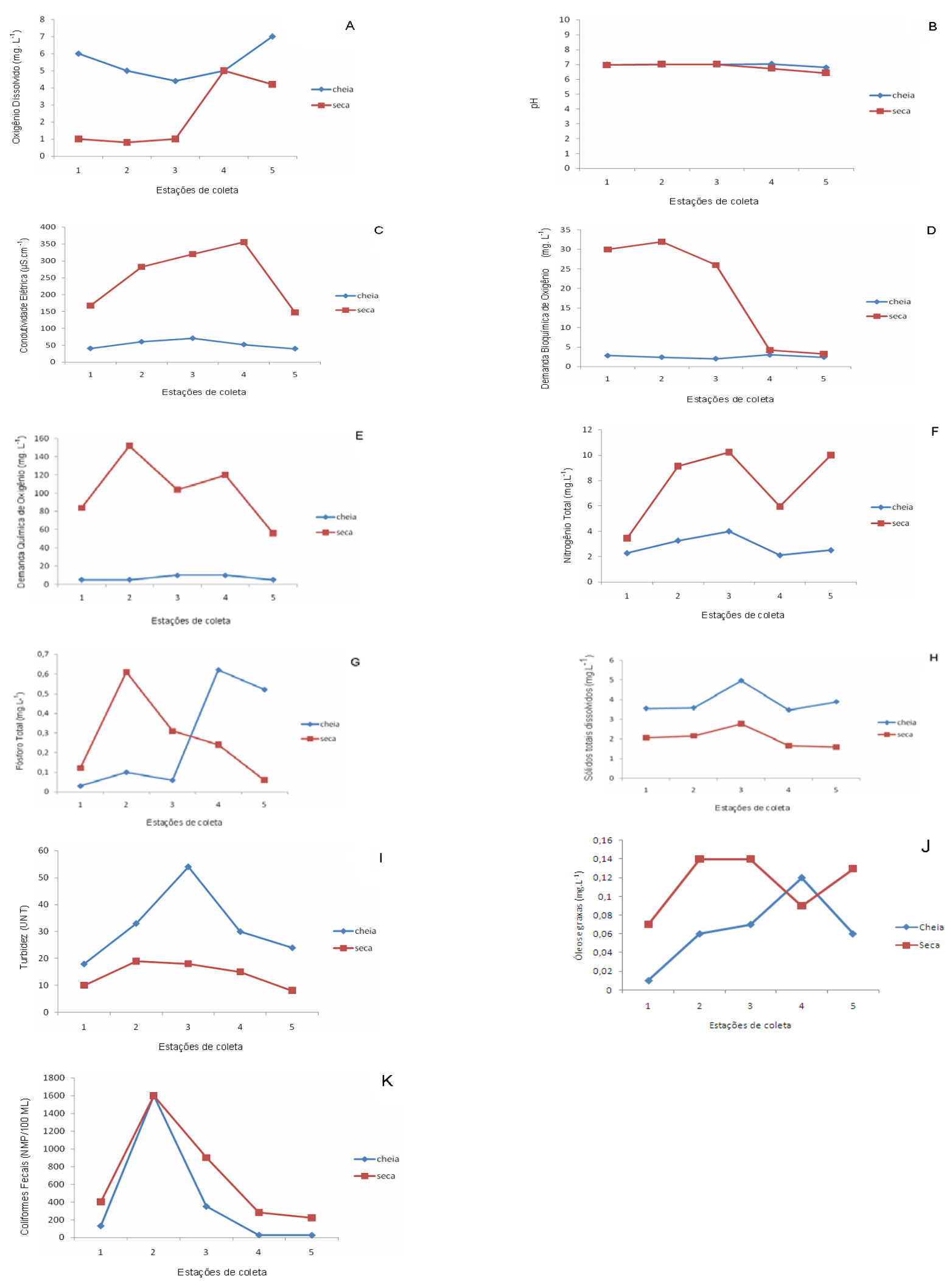

Figura 2. Variação espacial das parâmetros físicos e químicos (A-J) e Coliformes fecais (K) do Igarapé São Francisco. 

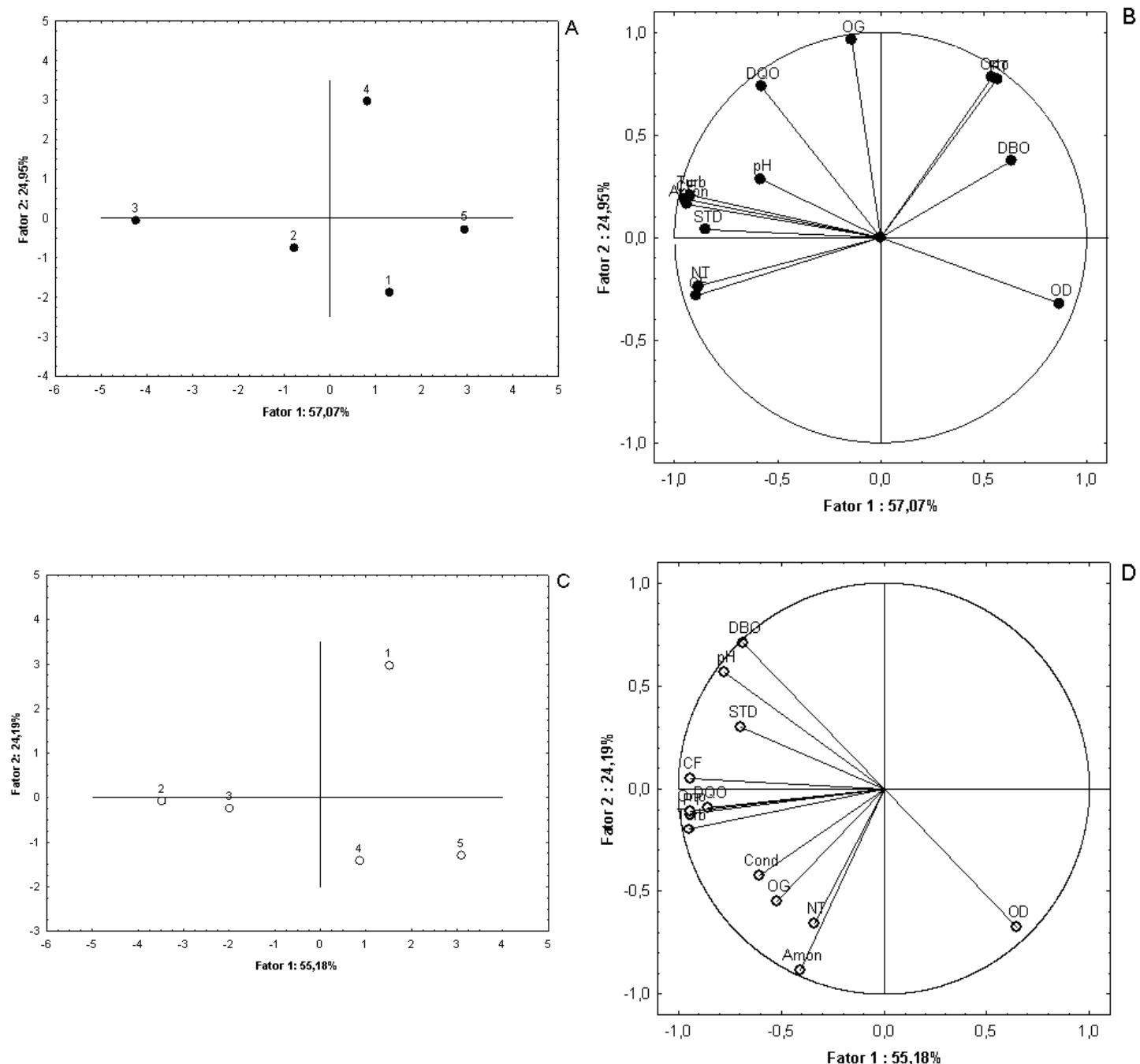

Figura 3. (A) Análise de componentes principais dos parâmetros físicos, químicos e bacteriológico em 5 (cinco) estações de coleta na época chuvosa no Igarapé São Francisco.

(B) Coeficientes de correlação entre os parâmetros físicos, químicos e biológicos na época chuvosa no Igarapé São Francisco.

(C) Análise de componentes principais dos parâmetros físicos, químicos e bacteriológico em 5 (cinco) estações de coleta na época seca no Igarapé São Francisco.

(D) Análise de componentes principais dos parâmetros físicos, químicos e bacteriológico em 5 (cinco) estações de coleta na época seca no Igarapé São Francisco.

\section{Conclusão.}

A oscilação do oxigênio foi significativa ao longo do trecho, tanto no período seco como no período chuvoso. As oscilações de $\mathrm{DBO}_{5}$ entre as estações chegaram a variar quase dez vezes, no período de seca.

Quanto aos nutrientes, o fósforo total fez-se presente em concentrações consideradas baixas nos dois períodos de coleta, tanto chuvoso como seco, alcançando grandes variações. Enquanto, o nitrogênio total apresentou maior concentração no período seco, provavelmente devido aos processos de decomposição da matéria orgânica, liberando compostos nitrogenados.
Os sólidos totais dissolvidos e turbidez apresentaram maiores valores no período chuvoso, o que era esperado devido ao pulso de inundação do igarapé.

A análise multivariada, em geral, não revelou tendência de agregação dos parâmetros físicos e químicos em eixos nos dois períodos avaliados, onde a época chuvosa revelou um padrão mais diferenciado, pois as variáveis se distribuíram quase uniformemente nos eixos positivo e negativo.

Os impactos na qualidade da água foram mais predominantes abaixo das pontes, pois nesses locais as intervenções foram mais pontuais. 
Referências Bibliográficas.

Ab’saber, A.N. 1985. Geomorfologia e paleoclimas da Amazônia brasileira. São Paulo: Apostila de Curso.

ABNT (Associação Brasileira de Normas Técnicas). 1989. NBR. 10664. Águas: Determinação de resíduos (sólidos) - Método gravimétrico.

ABNT (Associação Brasileira de Normas Técnicas). 1992. NBR. 12614. Águas: Determinação da Demanda Bioquímica de Oxigênio (DBO) Método de Incubação $\left(20^{\circ} \mathrm{C}\right.$, cinco dias). Rio de Janeiro.

Acre. Governo do Estado do Acre. 2000. Programa Estadual de Zoneamento Ecológico, Econômico do Estado do acre. Zoneamento Ecológico - Econômico: Recursos Naturais: Meio Ambiente - SECTMA. Rio Branco. v. 1.

Acre. 2005. Peça de criação da área de proteção ambiental (APA) igarapé São Francisco - Unidade de conservação de uso sustentável, Secretaria de Estado do Meio Ambiente - SEMA. Rio Branco. v. 1.

APHA. (American Public Health Association). 1992. Greenberg, A. E.; Clesceri, L. S.; Eaton, A. D. Standards methods for the examination of water and wastewater. 19. ${ }^{a}$ ed. AWWA, WES. Baltimore, Maryland.

APHA. (American Public Heath Association). 1995. Standard Methods for the Examination of Water and wastewater. 19a . ed. AWWA, WES. Baltimore, Maryland, USA.

Bassoi, L. J. \& Guazelli, M. R. 2004. Controle Ambiental da água. p. 53-100. En: Philippi Jr., A.; Romêro, M. A.; Bruna, G. C. Curso de Gestão Ambiental. Baureri: Manole, 2004

Blume, K.K.; Macedo, J.C.; Meneguzzi, A.; Silva, LB.; Quevedo, D.M. \& Rodrigues, M.A.S. 2010. Water quality assessment of the Sinos River, Southern Brazil. Brazilian Journal of Biology, v. 70, n. 4. p. 1185-1193.

Botalova, O. \& Schwarzbauer, J. 2011. Geochemical characterization of organic pollutants in effluents discharged from various industrial sources to riverine systems. Water, air e soil pollution. p.1-22.

Brasil. Conselho Nacional do Meio Ambiente - CONAMA. 2005. Resolução n. ${ }^{\circ}$ 357, de 17 de março de 2005. Diário Oficial da República federativa do Brasil, Brasília.

Brasil. Conselho Nacional do Meio Ambiente - CONAMA. 2000. Resolução no. 274, de 29 de novembro de 2000. Diário Oficial da República federativa do Brasil, Brasília.

Campanha, M. B., Melo, C. A., Moreira, A. B., Ferrarese, R. F. M. S., Tadini, A. M., Garbin, E. V. \& Bisinoti, M. C. 2010. Variabilidade espacial e temporal de parâmetros físico-químicos nos rios Turvo, Preto e Grande no Estado de São Paulo, Brasil. Química Nova, v. 33, n. 9. p. 1831-1836.

CETESB. Companhia de Tecnologia de Saneamento Ambiental. 1998. Guia de Preservação de Amostras de Águas. En: Agudo, E.G. (coord.). Secretaria de Estado do Meio Ambiente - SEMA. São Paulo.
Golterman, H.L. 1979. Methods of Chemical Analysis of Fresh Water. 2nd ed. I.B.P. Handbook, $N^{0}$. 9. Blackwell Scientific Publication, Oxford \& Edin-burgh.

Köppen, W. 1948. Climatologia. Fondo de Cultura Económica, México.

IDEAS. Instituto de Desenvolvimento e Estudos Aplicados à Seguridade. 1993. Levantamento preliminar da base de recursos naturais: Reserva Extrativista Chico Mendes. Brasília.

Menezes, J. M., Prado, R. B., Silva Jr., G. C., Mansur, K. L. \& Oliveira, E. S. 2009. Qualidade da água e sua relação espacial com as fontes de contaminação antrópicas e naturais: Bacia hidrográfica do rio São Domingos - RJ. Engenharia Agrícola, v. 29, n. 4. p. 687-698.

Nabil, J.E. 1982. Projeto contas ambientais da Amazônia: relatório de diagnóstico de climatologia e recursos hídricos. Brasília: SEMAN/PR, 1982.

Payne, A.I. 1986. The ecology of tropical lakes e rivers. New York: John Wiley \& Sons.

Pinto, A. G. N., Horbe, A. M. C., Silva, M. S.R., Miranda, S. A. F., Pascoalato, D. \& Santos, H. M.C. 2009. Efeitos da ação antrópica sobre a hidrogeoquímica do rio Negro na orla de Manaus, AM. Acta amazonica, v. 39, n. 3. p. 627-638.

Silva, G. S., Sousa, E. R., Konrad, C., Bem, C. C., Pauli, J. \& Pereira, A. 2009. Phosphorus and nitrogen in waters of the Ocoí River sub-basin, Itaipu Reservoir tributary. Journal Brazilian Chemical Society, v. 20, n. 9. p. 15801588.

Silva, A. E. P., Angelis, C. F., Machado, L. A. T., Waichaman, A. V. 2008. Influência da precipitação na qualidade da água do Rio Purus. Acta amazônica v. 38, n. 4. p.733-742.

Sioli, H. 1985. Amazônia: fundamentos da ecologia da maior região de florestas tropicais. Petrópolis: Vozes.

Sneath, P. H. \& Sokal, R. R. 1973. Numerical taxonomy. San Francisco: W.H. Freeman and Company.

Souza, G. A. C. 2010. Caracterização limnológica e índice de qualidade de água do balneário Igarapé Preto, localizado no Alto Juruá, Cruzeiro do Sul, AC. Monografia (Bacharelado em Ciências Biológicas). Universidade Federal do Acre (Cruzeiro do Sul-AC). 57p.

Souza, A. D. G. \& Tundisi, J. G. 2003. Water quality in watershed of the Joboatão River (Pernambuco, Brazil): a Case Study. Brazilian Archives of Biology and Technology: An international journal. v. 46, n. 4. p. 711721.

Statsoft, Inc. 2004. Statistica (data analysis software system), version 7. www.statsoft.com.

Wetzel, R. G. 1993. Limnologia. Fundação Calouste Gulbenkian, Lisboa.

Wetzel, R. G. 2002. Guest Comments: Human activities and the integrity of lake ecosystems. Water, air \& Soil pollution: focus. v. 2, n. 4. p. 7-8.

Wetzel \& Likens, G.E. 1991. Limnological analyses. 2.ed. New York: Springer-Verlag. 
1 Especialista em Engenharia de Saneamento Ambiental, Estrada Raimundo Irineu Serra, $n^{0}$. 37, Rio Branco, Acre, Brasil.

2 Universidade Federal do Acre, Campus de Rio Branco, Distrito Industrial, BR 364, Km, 04, Rio Branco, Acre, Brasil.

3 Universidade Federal do Acre, Campus de Cruzeiro do Sul, Acre, Canela Fina, Cruzeiro do Sul, Acre, Brasil. erleikeppeler@gmail.com 